\title{
Complex comprised of dextran magnetite and conjugated cisplatin exhibiting selective hyperthermic and controlled-release potential
}

This article was published in the following Dove Press journal:

International Journal of Nanomedicine

10 July 2010

Number of times this article has been viewed

\author{
Akinaga Sonoda' \\ Norihisa Nitta' \\ Ayumi Nitta-Seko' \\ Shinich Ohta' \\ Shigeyuki Takamatsu ${ }^{2}$ \\ Yoshio Ikehata ${ }^{3}$ \\ Isamu Nagano ${ }^{3}$ \\ Jun-ichiro Jo ${ }^{4}$ \\ Yasuhiko Tabata ${ }^{4}$ \\ Masashi Takahashi ${ }^{1}$ \\ Osamu Matsui ${ }^{3}$ \\ Kiyoshi Murata'
}

'Department of Radiology, Shiga University of Medical Science, Setatsukinowa-cho, Otsu, Shiga, 520-2192, Japan; ${ }^{2}$ Department of Radiology, Graduate School of Medical Science, Kanazawa University, Takaramachi I3-I, Kanazawa Ishikawa, 920-864 I, Japan; ${ }^{3}$ Department of Natural Science and Technology, Kanazawa University, Kakuma-machi, Kanazawa, Ishikawa 920-I I 92, Japan; ${ }^{4}$ Department of Biomaterials, Institute for Frontier Medical Sciences, Kyoto University, Shogoin kawara-machi 53. Sakyo-ku 606-8507, Kyoto, Japan Graduate School of Engineering, Department of Radiology, Shiga University of Medical Science, Setatsukinowa-cho, Otsu, Shiga 520-2192, Japan

Tel +8I-77-548-2285

Fax +8I-77-544-0986

Email akinaga@belle.shinga-med.ac.jp
Correspondence:Akinaga Sonoda

\begin{abstract}
We developed a dextran-magnetite conjugated cisplatin (DM-Cis) complex for use in thermal ablation and as a chemotherapeutic drug. To produce DM-Cis we reacted Cis with $1 \mathrm{~mL}$ $\mathrm{DM}(56 \mathrm{mg} / \mathrm{mL}$ iron). The temperature rise of DM-Cis was measured in vitro and in vivo under a portable induction-heating $(\mathrm{IH})$ device. Platinum desorption from DM-Cis over 24 hours was measured in bovine serum. In in vivo accumulation and magnet and exothermic experiments we used four rat groups. In group 1 we delivered DM-Cis intraperitoneally (ip) and placed magnets subcutaneously (sc). In group 2 we injected saline (ip) and placed magnets (sc). In group 3 we injected DM-Cis (ip) and placed a sc incision (sham). The control (group 4) received an ip injection of saline. Rectus abdominis muscle tissue was stained with hematoxylin-eosin and iron-stained tissue areas $\left(\mu \mathrm{m}^{2}\right)$ were calculated. The maximum platinum concentration in DM-Cis was approximately $105.6 \mu \mathrm{g} / \mathrm{mL}$. Over 24 hours, $33.48 \%$ of platinum from DM-Cis was released. There was a significant difference $(P<0.05)$ in the iron-stained area between group 1 and the other groups. The temperature in muscle tissue registered a maximum of $56^{\circ} \mathrm{C}$ after about $4 \mathrm{~min}$. DM-Cis may represent a magnetically-accumulated anticancer drug with hyperthermic effects.
\end{abstract}

Keywords: magnetic nanoparticle-conjugated anticancer agents, DM, portable induction heating device, carboxyl group, rat

\section{Introduction}

The purpose of this study was to develop a DM-Cis complex and to examine the possibility of using DM-Cis for hyperthermic treatment and chemotherapy.

Magnetic nanoparticles have been used to diagnose tumors in the liver and spleen by magnetic resonance imaging (MRI). ${ }^{1}$ The in vivo accumulation of these particles in specific areas has been studied and the feasibility of hyperthermic treatment with magnetic particles has been investigated. ${ }^{2-10}$ As magnetic nanoparticles convert energy absorbed from an alternating magnetic field into heat, they may be useful for the delivery of hyperthermic therapy. Murata et $\mathrm{al}^{11}$ reported that anticancer agents delivered intraductally via the nipple may facilitate the administration of neoadjuvant therapy in patients with early breast cancer. We hypothesized that the availability of magnetic nanoparticle-conjugated anticancer agents may make it possible to treat various breast cancers by their intraductal administration and that this treatment would elicit hyperthermic effects.

DM is used widely as a liver-specific contrast medium (Resovist ${ }^{\circledR}$; Bayer Health Care Japan, Osaka, Japan) and its safety has been established. ${ }^{1,8}$ DM consists of carboxy-dextran, which covers the core and the iron-oxide particles of the core. Therefore, a carboxyl group originating from dextran is present on the particle surface. 
The possibility of conjugating DM with the carboxyl group of gelatin and $\mathrm{Cis}$ was raised and gelatin-conjugated Cis was found to release Cis slowly, thereby potentially maximizing its anti-tumor effects. ${ }^{12,13}$ (Figure 1).

\section{Methods}

\section{Preparation of DM-Cis}

A 1:1 ratio was defined as $1 \mathrm{~mL}$ Cis $(1.43 \mathrm{mg} / \mathrm{mL}$ Cis $)$ (Nippon Kayaku Co., Tokyo, Japan) to $1 \mathrm{~mL}$ DM (56 mg/mL iron) (Meito, Aichi, Japan). We reacted various amounts of Cis with $1 \mathrm{~mL}$ DM. Initially we titrated Cis slowly into DM and followed this procedure with 7-day incubation at $37^{\circ} \mathrm{C}$. In subsequent experiments we dialyzed the solution in $10 \mathrm{~L}$ of ultrapure double-distilled water (UDDW), exchanging the water 10 times in 7 days; we employed cellulose dialysis tubing (MWCO14000; Viskase Co. Inc., IL, USA) and removed residual unconjugated $\mathrm{Cis}$. The platinum concentration of DM-Cis was measured on an AA-6800 atomic absorption spectrometer (Shimadzu, Kyoto, Japan). When DM was reacted with $C$ is at a 1:1 ratio, we determined the size of the DM-Cis complex based on dynamic light scattering (DLS; light wave length $514 \mathrm{~nm}$, sample temperature $25^{\circ} \mathrm{C}$; Autosizer 4700, Malvern Instruments, Worcestershire, UK).

\section{Exothermic experiment under}

\section{a magnetic field}

A portable $\mathrm{IH}$ device (alternating current (AC), $142 \mathrm{KHz}$ magnetic field, single-phase, AC $200 \mathrm{~V}$, electric current 440
Amp, power consumption $3.5 \mathrm{~kW}$ ) was the magnetic field generator. $^{7}$ After reacting $2.5 \mathrm{~mL}$ Cis with $2.5 \mathrm{~mL} \mathrm{DM}$, we introduced a polyurethane tube containing $5 \mathrm{~mL}$ DM-Cis into the $20-\mathrm{cm}$ diameter $\mathrm{IH}$ coil, set the IH device at $142 \mathrm{KHz}$, and measured the temperature for 10 minutes by inserting a thermometer (FL-2000; Anritsu Meter, Tokyo, Japan) into the tube.

\section{Desorption of platinum from DM-Cis in bovine serum}

DM-Cis $(3 \mathrm{~mL})$ in cellulose dialysis tubing was immersed in bovine serum ( $9 \mathrm{~mL}$ ) and shaken reciprocally ( 72 strokes $/ \mathrm{min})$ at $37^{\circ} \mathrm{C}$. At $30 \mathrm{~min}$ and $1,3,6,12$, and 24 hours we withdrew $0.5-\mathrm{mL}$ bovine serum samples and immediately replaced them with the same volume of fresh bovine serum. The platinum concentration in the samples was then measured on an AA-6800 atomic absorption spectrometer (Shimadzu, Kyoto, Japan).

\section{In vivo accumulation and magnet and exothermic experiments}

All experimental protocols were approved by our animal experimentation committee and all experiments were conducted in accord with the Animal Care Guidelines of Shiga University of Medical Science.

\section{Production of the magnet-bearing rat model}

Wistar rats (SLC, Tokyo, Japan) were housed for more than one week in solid-floor cages in a dedicated pathogen-free

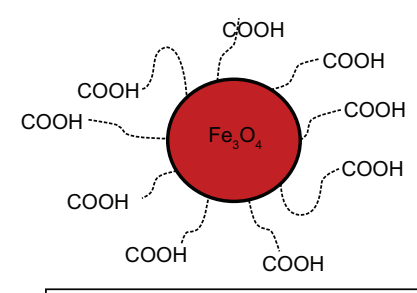

Dextran-magnetite (DM)

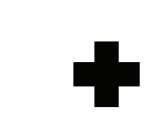

${ }_{\mathrm{Cl}}^{\mathrm{Cl}} \overbrace{\mathrm{Pt}}{ }_{\mathrm{NH}_{3}}^{\mathrm{NH}_{3}}$

Cisplatin
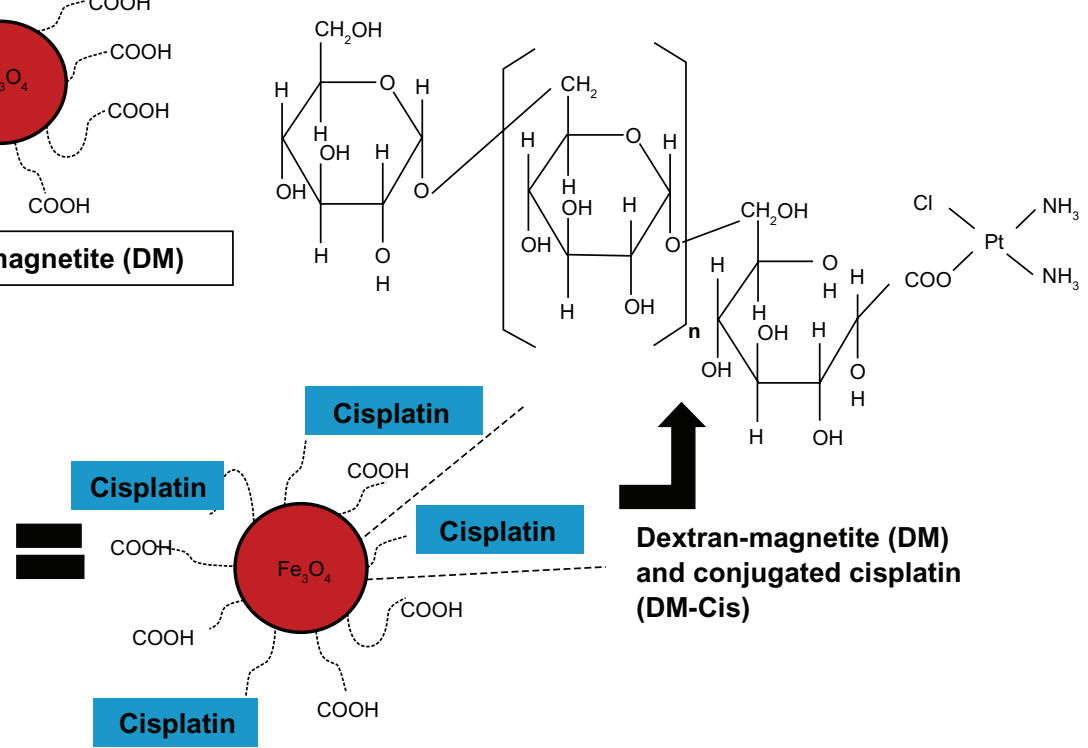

Dextran-magnetite (DM) and conjugated cisplatin (DM-Cis)

Figure I Illustration of a complex comprised of DM and conjugated Cis. A carboxyl group originating from dextran exists partially on the particle surface. The conjugation of DM with the carboxyl group of Cis may result in a slow release of Cis, thereby potentially maximizing its anti-tumor effect. 
animal facility at the Research Center for Animal Life Science of our institution. The bedding was highly absorbent, free of materials toxic to humans and animals, and unpalatable to the animals. We provided sufficient bedding to keep the animals dry and unsoiled by feces and urine, the bedding did not interfere with the animals' drinking. All bedding was stored on pallets to avoid contact with the floor. The room temperature was controlled at $22^{\circ} \mathrm{C} \pm 4$. The relative humidity was controlled at $40 \%-70 \%$. The rats received a diet of commercially available pellets and water ad libitum.

The animals were anesthetized with an ip injection of pentobarbital (40 mg/kg, Dai Nippon Sumitomo Pharma Co. Ltd., Tokyo, Japan). In six randomly selected rats from groups 1 and 2 (three rats/group) we placed a $1-\mathrm{cm} \mathrm{sc}$ incision to create a pocket in the right lower quadrant for neodymium magnets ( 0.3 Tesla, $1 \times 1 \times 0.5 \mathrm{~cm}$, Niroku Seisakusho, Shiga, Japan). Another 6 rats from groups 3 and 4 (3 rats/group) served as the control; they received similar sc incisions but no magnets were placed (Table 1). After the operation, all rats were injected intramuscularly with enrofloxacin $(2.5 \%, 1 \mathrm{~mL}$; Baytril $^{\circledR}$, Bayer Healthcare Co. Ltd., Tokyo, Japan) once a day for three consecutive days. On the seventh postoperative day they were used for the therapy portion of our study.

\section{DM-Cis accumulation experiment after ip administration}

Four days after the ip injection of $1 \mathrm{~mL}$ saline (groups 2 and 4, 3 rats/group) or $1 \mathrm{~mL}$ DM-Cis (groups 1 and 3, three rats/ group) into the left upper quadrant (Table 1) all rats were sacrificed with pentobarbital (400 mg/kg, ip; Dai Nippon Sumitomo Pharma Co.). The magnets were removed, rectus abdominis muscle tissue just under the pocket was harvested, fixed in 10\% buffered formalin for 24 hours, and embedded in paraffin. A 4- $\mu \mathrm{m}$-thick slice of a sagittal section relative to the magnets was deparaffinized and stained with hematoxylin and eosin ( $\mathrm{H}$ and $\mathrm{E}$ ) and Berlin blue for the detection of iron. The iron-stained area $\left(\mathrm{um}^{2}\right)$ was calculated using Image-Pro Plus (Media Cybernetics, MD, USA). We extracted blue-stained portions from the muscle tissues (threshold: red 0-110, green 0-250, blue 0-250), computed the blue-stained area in

Table I Protocol of the DM-Cis accumulation experiment

\begin{tabular}{lll}
\hline Groups & $\begin{array}{l}\text { Magneto flasking } \\
\text { subcutaneously }\end{array}$ & $\begin{array}{l}\text { Intraperitoneal } \\
\text { injection of DM-Cis }\end{array}$ \\
\hline I (Magnet/ip) & + & + \\
2 (Magnet) & + & - \\
3 (ip) & - & + \\
4 (Control) & - & - \\
\hline
\end{tabular}

one view (X100), recorded the average of 5 view areas, and evaluated the area stained positively for iron. For statistical analysis we used Dr SPSS II for Windows (SPSS Japan Inc., Tokyo, Japan). Significant differences in the iron-stained areas among groups of rats were determined with Tukey's HSD test. A $P$ value of $<0.05$ was considered to indicate a significant difference.

\section{In vivo exothermic experiment}

Four rats were injected ip with DM-Cis and magnets were placed sc (Table 1). After 24 hours the magnets were removed from the pockets and 18-gauge venula catheter needles were inserted into the rectus abdominis muscle tissue just under the pocket to fix the thermometer (FL-2000; Anritsu Meter, Tokyo, Japan) at the target site. One thermometer was used to monitor the temperature in the rectus abdominis muscle tissue just under the pocket and another, inserted into the rectum, to monitor the rectal temperature. These rats were placed into the IH coil for temperature measurements.

\section{Results Size of DM-Cis}

The diameter of the DM-Cis complex was $59.6 \pm 0.4 \mathrm{~nm}$ ( \pm mean standard deviation).

\section{Platinum concentration in DM-Cis}

Defining $1 \mathrm{~mL} \mathrm{DM}$ to $1 \mathrm{~mL}$ Cis as a ratio of $1: 1$, the concentration of platinum at 1.0:0.05, 1.0:0.1, 1.0:0.5, and 1:1 (DM:Cis) was $11.66 \pm 1.13,17.54 \pm 1.84,80.83 \pm 2.91$, and $105.60 \pm 9.03 \mathrm{ug} / \mathrm{mL}$, respectively (Figure 2).

\section{In vitro exothermic experiment using a magnetic field}

Under the portable IH device, the DM-Cis $(5 \mathrm{~mL}$, DM: Cis $=1: 1(\mathrm{v}: \mathrm{v})$ solution could be heated at a rate of $0.12^{\circ} \mathrm{C} /$ sec. The temperature rose to $60^{\circ} \mathrm{C}$ in approximately $5 \mathrm{~min}$ (Figure 3).

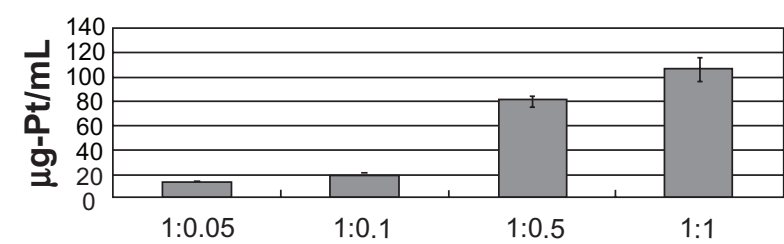

Figure 2 Conjugated concentration of platinum in the DM complex. Defining I $\mathrm{mL}$ DM to $1 \mathrm{ml}$ Cis as a $\mathrm{l}: \mathrm{I}$ ratio, this graph shows the concentration of platinum at I.0:0.05, I.0:0.1, I.0:0.5, and I:I (DM:Cis). The platinum concentration at the applied concentrations of platinum conjugated with DM was $11.66 \pm 1.13,17.54 \pm 1.84$, $80.83 \pm 2.91$, and $105.60 \pm 9.0 \mathrm{ug} / \mathrm{mL}$, respectively. 


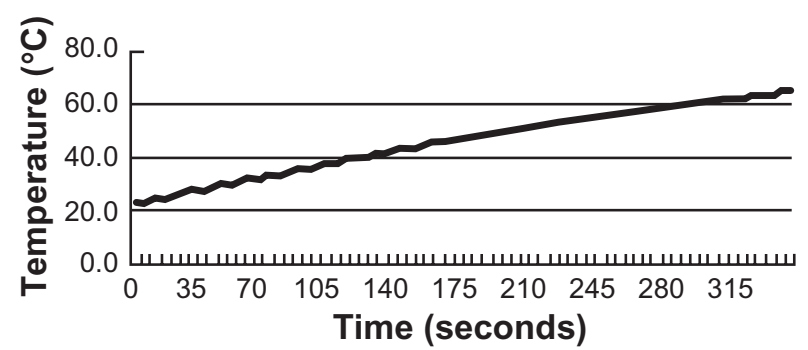

Figure 3 The temperature of DM-Cis under a portable $\mathrm{IH}$ device. Under the $\mathrm{IH}$ device, DM-Cis $(5 \mathrm{~mL}, \mathrm{DM}: \mathrm{Cis}=\mathrm{I}: \mathrm{I})$ could be heated at a rate of $0.12^{\circ} \mathrm{C} / \mathrm{sec}$. The temperature was maintained at $60^{\circ} \mathrm{C}$ for 5 minutes.

\section{Concentration and desorption of platinum from DM-Cis in bovine serum}

Approximately $0.58,1.20,4.42,9.30,16.42$, and $33.48 \%$ of platinum in DM-Cis was released at $30 \mathrm{~min}$ and at 1, 3,6, 12, and 24 hours, respectively. The platinum concentration in the solution remaining in the dialysis tube was $65.32 \%$ of the total amount of platinum (Figure 4).

\section{In vivo intraperitoneal accumulation}

In group 1 we observed an extraordinary accumulation of DM-Cis in the peritoneum just under the magnet (Figure 5). There was no such accumulation in the other groups (data not shown). In addition, there was a significant difference between group 1 and the other groups with respect to the accumulation of DM-Cis in muscle tissues (Figure 6).

\section{In vivo exothermic experiment}

Figure 7 shows the individual temperature profiles in rectus abdominis muscle tissue just under the pocket and in rectal tissue. The temperature in muscle tissues was maintained at a maximum of $56^{\circ} \mathrm{C}$ after 4 minutes. The rectal temperature elevation was slight. No rats died from exposure to high heat or electromagnetic waves.

\section{Discussion}

We developed a DM-Cis complex that manifests hyperthermic effects and is manipulated magnetically in the abdominal cavity of rats and at elevated temperatures in vivo under the IH system.

The size of the DM-Cis complex was $59.6 \pm 0.4 \mathrm{~nm}$. As DM measures $55.7 \mathrm{~nm}$, there was apparently no DM-Cis aggregation. While aggregates of this DM-Cis complex may not spread well in breast ducts, the size of the formed DM-Cis complex can be expected to remain stable.

When we reacted DM with Cis at a 1:1 ratio, the platinum concentration of DM-Cis (DM:Cis = 1:1) was $105.60 \pm$ $9.03 \mathrm{ug} / \mathrm{mL}$, approximately $32 \%$ of the platinum concentration in a pharmaceutical Cis preparation (Randa ${ }^{\circledR}$, Nippon Kayaku Co. Ltd, Tokyo, Japan). The Cis concentration in DM-Cis is relatively high, rendering it clinically useful. Under the $\mathrm{IH}$ device, the temperature of DM-Cis in vitro rose to $60^{\circ} \mathrm{C}$ or more in approximately $5 \mathrm{~min}$. At that temperature there are obvious hyperthermic effects. However, to be useful, Cis must be released from the DM-Cis complex. We found that in the

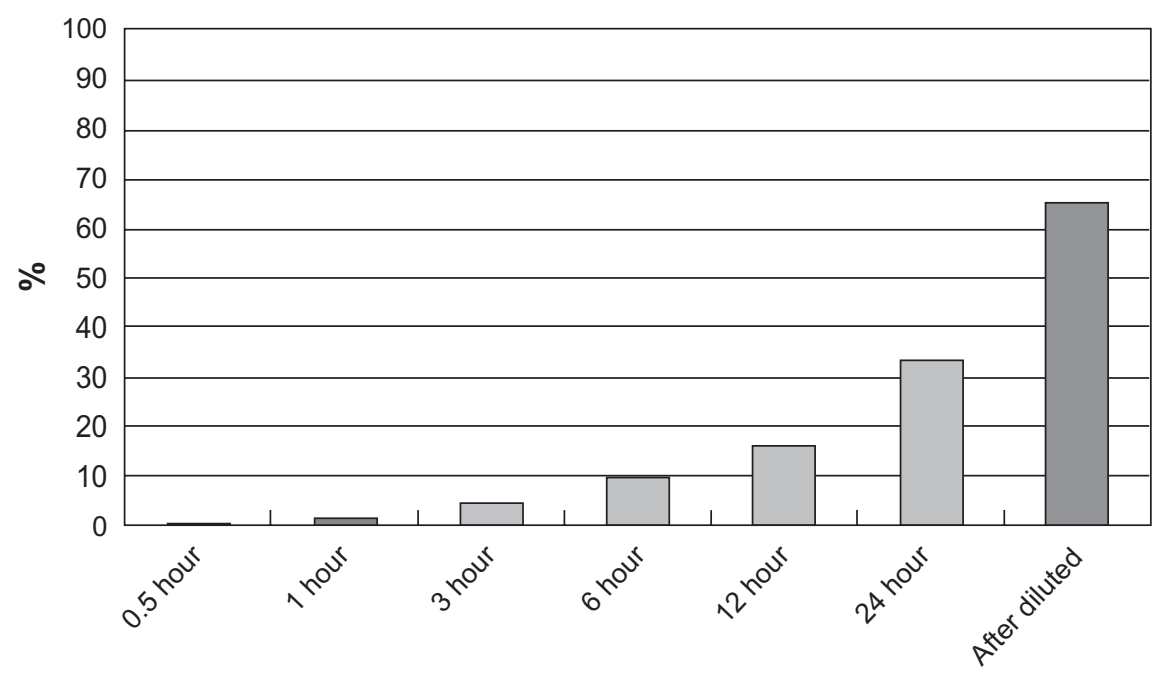

Pt disportion rate from DM-Cis

Figure 4 Time course of platinum release from DM-Cis in bovine serum. Approximately $0.58,1.20,4.42,9.30$, 16.42, and 33.48\% of platinum in DM-Cis was released at 30 minutes and at I, 3, 6, I2, and 24 hours, respectively. 

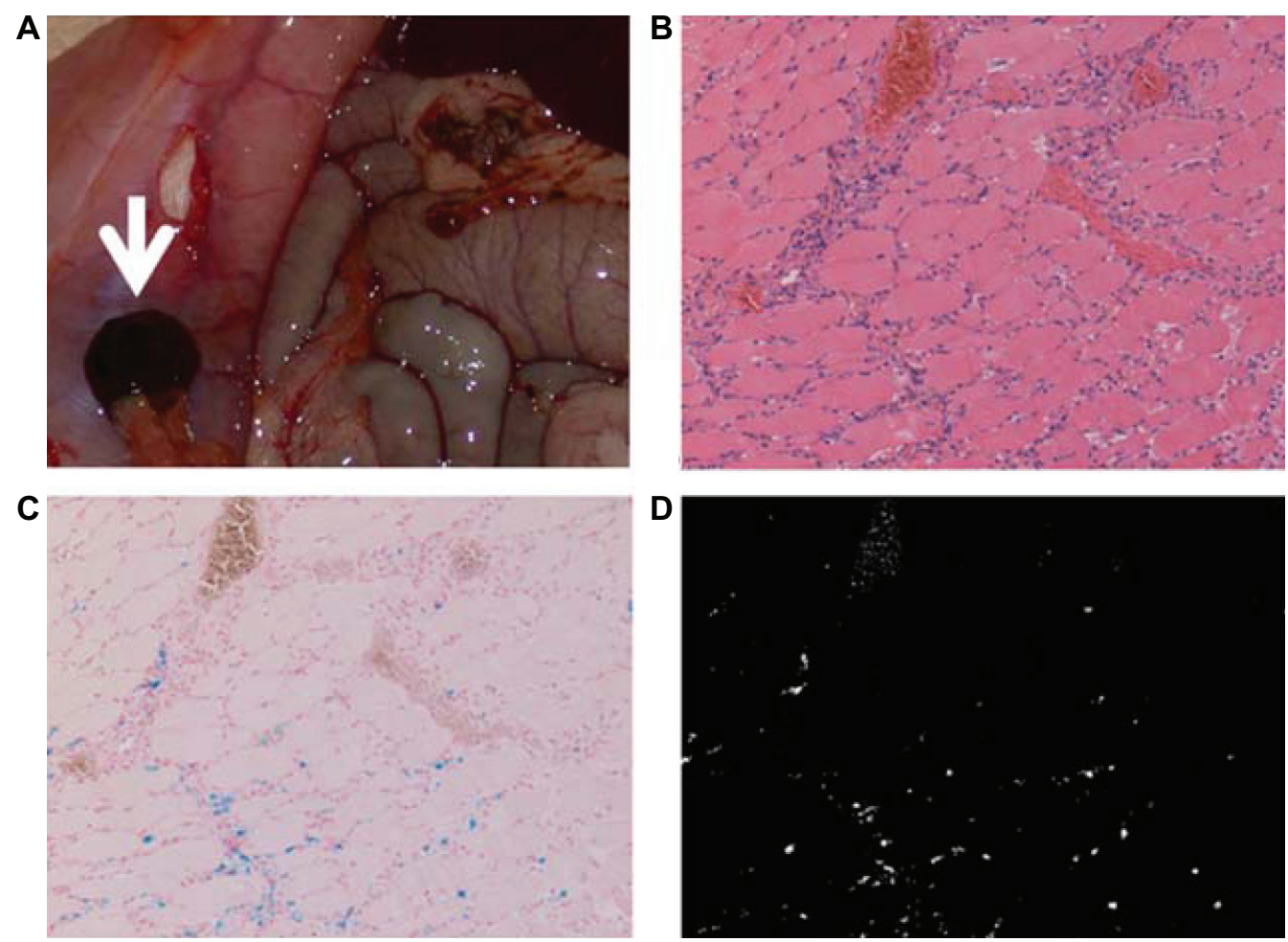

Figure 5 Accumulation of DM-Cis in group I rats. a) Macroscopic image of DM-Cis accumulation in the peritoneum. b) $\mathrm{H}$ \& $\mathrm{E}$ stains (XI00) of rectus abdominis muscle tissue just under the pocket harboring the magnets. Note the aggregation of phagocytes in muscle tissue. c) Berlin-blue stains (XI00). Iron distributed in the muscle tissues is blue. d) Masked image using Image-Pro Plus. Only portions dyed blue are identified by white dots using Image-Pro Plus.

course of 24 hours, approximately $30 \%$ of Cis was desorbed in bovine serum, suggesting that the continued presence of Cis enhances its anti-tumor effects. In addition, DM-Cis accumulated in the rat peritoneum in a 0.3 Tesla magnetic field and as in muscle tissues just under the DM-Cis area, the iron concentration was clearly increased. It may be possible to trap DM-Cis for prolonged periods with a magnet in ducts and main tumor areas. The maximum temperature was $56^{\circ} \mathrm{C}$ and the area of hyperthermia was concentrated just beneath the in vivo DM-Cis accumulation site. For thermal treatment,

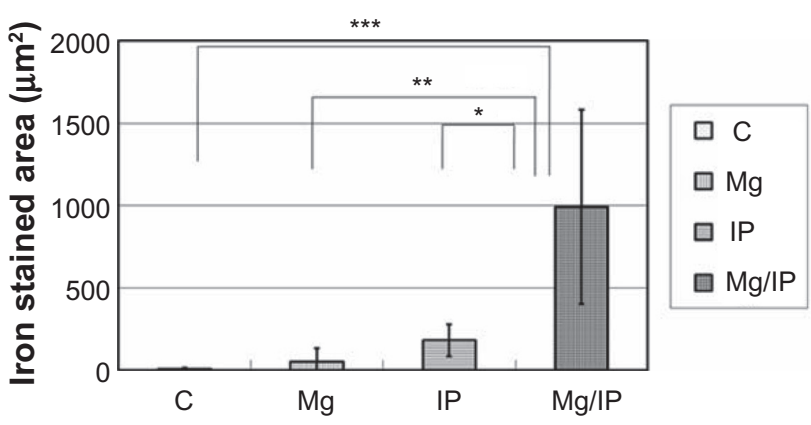

Figure 6 Total iron-stained area $\left(\mu \mathrm{m}^{2}\right)$. Group I differed significantly from the other three groups with respect to the iron-stained area in muscle tissues $\left(P<0.05^{* * w_{*}, * \ldots+k}\right)$. There was no significant difference among groups 2,3 , and 4 . temperatures of approximately $42^{\circ} \mathrm{C}$ are considered sufficient to induce anti-tumor effects. ${ }^{14} \mathrm{~A}$ temperature rise to $56^{\circ} \mathrm{C}$ may coagulate targeted tissues directly. ${ }^{15}$

In one rat the temperature rose to $40.7^{\circ} \mathrm{C}$ in the rectus abdominis muscle tissue located just under the pocket. This raises the concern that some infused DM-Cis may be accidentally injected into sc tissue, resulting in a decrease in the total

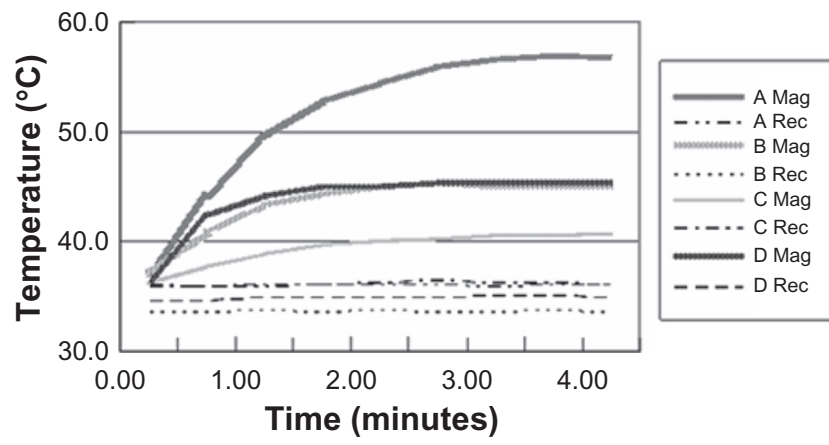

Figure 7 Temperature profiles of muscle and rectal tissues under the portable $\mathrm{IH}$ device. Group I rats $(n=4)$ were placed into the $\mathrm{IH}$ coil and the temperature was increased to $46.98 \pm 7.0^{\circ} \mathrm{C}$ on average. The temperature in muscle tissues reached a maximum of $56^{\circ} \mathrm{C}$ after $4 \mathrm{~min}$. The temperature increase in rectal tissue was slight. None of the experimental rats died from exposure to high heat or electromagnetic waves. 
amount of DM-Cis accumulated in the peritoneum and a lowering of the heat value. In another three rats, the temperature rise was sufficient to achieve hyperthermic effects. Moreover, these temperature gains were produced within 5 minutes, but according to others, ${ }^{6,7}$ the time required for similar temperature increases was longer. Our technique makes it possible to avoid raising the temperature in other parts of the body. None of our rats died during the heating procedure, suggesting the clinical applicability of this technique. Slow-release antitumor drugs with hyperthermic potential that can be magnetically manipulated and collected may be a more effective treatment of some cancers than surgical resection.

Our study has some limitations. Firstly, we did not compare the anti-tumor effects of DM-Cis in vivo and in vitro. Although Cis-conjugated gelatin maintained its anti-tumor effects in vivo, ${ }^{13}$ we need to determine whether Cis-conjugated DM also retains these effects. Studies are underway in our laboratory to examine its effects in experimental mouse breast carcinoma. Secondly, we did not carry out ductal accumulation experiments. As ductal is slower than blood vessel flow, we posit that DM-Cis may fully accumulate magnetically. We are testing this hypothesis in a murine breast carcinoma model in which we administer DM-Cis via mammary ducts. Thirdly, we did not quantify the relationship between the concentration of accumulated iron and the distance between the site of accumulation and the site of temperature elevation. Our purpose in the current study was to examine whether DM-Cis can generate heat in vivo to the degree at which hyperthermia is induced. Fourthly, the long-term safety of DM-Cis remains to be established. However, as both DM and Cis are used clinically, these materials have been shown to be safe. We will perform additional experiments to address this issue. And finally, our study sample was deliberately small because our experiments to determine whether DM-Cis can generate heat in vivo exposed the animals to significant distress.

\section{Disclosure}

The authors report no conflicts of interest in this work.

\section{References}

1. Kopp AF, Laniado M, Dammann F, et al. MR imaging of the liver with Resovist: safety, efficacy, and pharmacodynamic properties. Radiology. 1997;204(3):749-756.

2. Kobeiter H, Georgiades CS, Leakakos T, et al. Targeted transarterial therapy of Vx-2 rabbit liver tumor with Yttrium-90 labeled ferromagnetic particles using an external magnetic field. Anticancer Res. 2007; 27(2):755-760.

3. Jordan A, Wust P, Fahling H, et al. Inductive heating of ferrimagnetic particles and magnetic fluids: physical evaluation of their potential for hyperthermia. Int J Hyperthermia. 1993;9(1):51-68.

4. Moroz P, Jones SK, Winter J, et al. Targeting liver tumors with hyperthermia: ferromagnetic embolization in a rabbit liver tumor model. J Surg Oncol. 2001;78(1):22-49; discussion 30-31.

5. Moroz P, Metcalf C, Gray BN. Histologic analysis of liver tissue following hepatic arterial infusion of ferromagnetic particles in a rabbit tumour model. Biometals. 2003;16(3):455-464.

6. Motoyama J, Yamashita N, Morino T, et al. Hyperthermic treatment of DMBA-induced rat mammary cancer using magnetic nanoparticles. Biomagn Res Technol. 2008;6:2.

7. Takamatsu S, Matsui O, Gabata T, et al. Selective induction hyperthermia following transcatheter arterial embolization with a mixture of nano-sized magnetic particles (ferucarbotran) and embolic materials: feasibility study in rabbits. Radiat Med. 2008;26(4):179-187.

8. Wada S, Yue L, Tazawa K, et al. New local hyperthermia using dextran magnetite complex (DM) for oral cavity: experimental study in normal hamster tongue. Oral Dis. 2001;7(3):192-195.

9. Mitsumori M, Hiraoka M, Shibata T, et al. Development of intra-arterial hyperthermia using a dextran-magnetite complex. Int J Hyperthermia. 1994;10(6):785-793.

10. Mitsumori M, Hiraoka M, Shibata T, et al. Targeted hyperthermia using dextran magnetite complex: a new treatment modality for liver tumors. Hepatogastroenterology. 1996;43(12):1431-1437.

11. Murata S, Kominsky SL, Vali M, et al. Ductal access for prevention and therapy of mammary tumors. Cancer Res. 2006;66(2):638-645.

12. Sonoda A, Nitta N, Ohta S, et al. Development of a conjugated gadolinium and cisplatin-gelatin possessing properties as an intravascular contrast agent for MR imaging. Eur J Radiol. 2009;71(3): 570-575.

13. Konishi M, Tabata Y, Kariya M, et al. In vivo anti-tumor effect of dual release of cisplatin and adriamycin from biodegradable gelatin hydrogel. J Control Release. 2005;103(1):7-19.

14. Hilger I, Hergt R, Kaiser WA. Use of magnetic nanoparticle heating in the treatment of breast cancer. IEE Proc Nanobiotechnol. 2005; 152(1):33-39.

15. Heisterkamp J, van Hillegersberg R, Ijzermans JN. Critical temperature and heating time for coagulation damage: implications for interstitial laser coagulation (ILC) of tumors. Lasers Surg Med. 1999;25(3): 257-262.
International Journal of Nanomedicine

\section{Publish your work in this journal}

The International Journal of Nanomedicine is an international, peerreviewed journal focusing on the application of nanotechnology in diagnostics, therapeutics, and drug delivery systems throughout the biomedical field. This journal is indexed on PubMed Central, MedLine, CAS, SciSearch $\AA$, Current Contents ${ }^{\circledR} /$ Clinical Medicine,

\section{Dovepress}

Journal Citation Reports/Science Edition, EMBase, Scopus and the Elsevier Bibliographic databases. The manuscript management system is completely online and includes a very quick and fair peer-review system, which is all easy to use. Visit http://www.dovepress.com/ testimonials.php to read real quotes from published authors. 